\title{
IL-6-producing Renal Cell Carcinoma Causing Renal and Endocrine Paraneoplastic Syndromes
}

\author{
Akira Okada $^{1,2}$, Takaaki Higashihara ${ }^{1,2}$, Taiko Kusano ${ }^{2,3}$, Koji Takemura ${ }^{1,2}$, \\ Hanako Saigusa $^{1,2}$, Sayako Maruno ${ }^{2}$, Mimiko Matsumura ${ }^{2}$, Takeo Suzuki ${ }^{4}$, \\ Akira Shimizu $^{5}$ and Hideki Takano ${ }^{2}$
}

\begin{abstract}
:
An 83-year-old man with stable chronic kidney disease (CKD) exhibited a sudden increase in urinary Nacetyl- $\beta$-D-glucosaminidase and protein excretion, suggesting aggravated kidney damage. Simultaneously, he lost diabetic control, requiring up to 54 units of insulin daily. A detailed examination revealed the presence of renal cell carcinoma, which was surgically resected and confirmed to be interleukin-6-positive by immunohistochemistry. Postoperatively, his uni-nephrectomy necessitated hemodialysis, but the patient's insulin resistance was ameliorated; no medication was required to control diabetes, suggesting that the tumor had caused the insulin resistance. This report describes a case of a tumor secreting interleukin-6, which affects both the control of diabetes and CKD progression.
\end{abstract}

Key words: interleukin-6 (IL-6), chronic kidney disease (CKD), diabetes mellitus, insulin resistance, renal cell carcinoma, paraneoplastic syndrome

(Intern Med 58: 1953-1960, 2019)

(DOI: 10.2169/internalmedicine.2000-18)

\section{Introduction}

Acute kidney injury (AKI) in chronic kidney disease (CKD) is a strong contributing factor to CKD progression, which ultimately leads to end-stage kidney disease (ESKD) (1). AKI is also a serious complication in patients with various cancer types (most often kidney cancer) and may incur the need for renal replacement therapy (RRT) (2). Furthermore, cancer development may increase insulin resistance, leading to the aggravation of an underlying diabetic condition, while also promoting continued cancer progression (3). In fact, diabetic kidney disease is the leading cause of ESKD in the United States (US) (3); thus, new clinical modalities to ameliorate the effects of cancer-induced AKI and those of increased insulin resistance in patients with diabetes are urgently needed. Notably, the development of various cancers has been shown to intersect with the pro- gression of diabetes mellitus. Although the mechanisms by which these malignancies aggravate diabetes have not yet been elucidated, proinflammatory factors such as interleukin-6 (IL-6) have been shown to promote the progression of both conditions (4-6).

To our knowledge, the present study is the first to report a link between diabetes, CKD, and cancer progression in a single patient. The present findings highlight the need for increased cancer screening in patients with concomitant diabetes and CKD progression.

\section{Case Report}

An 83-year-old man with a performance status of 3 as defined by the Eastern Cooperative Oncology Group (7) regularly visited our hospital for treatment for diabetes-induced CKD over a couple of decades. He presented with medication-controlled hypertension and insulin-independent

\footnotetext{
${ }^{1}$ Division of Nephrology and Endocrinology, The University of Tokyo Graduate School of Medicine, Japan, ${ }^{2}$ Department of Nephrology, Tokyo Teishin Hospital, Japan, ${ }^{3}$ Department of Internal Medicine, Kasuganokai Hospital, Japan, ${ }^{4}$ Department of Interventional Radiology, Tokyo Teishin Hospital, Japan and ${ }^{5}$ Department of Analytic Human Pathology, Graduate School of Medicine, Nippon Medical School, Japan Received: August 23, 2018; Accepted: January 9, 2019; Advance Publication by J-STAGE: March 28, 2019 Correspondence to Dr. Akira Okada, aokada-tky@umin.ac.jp
} 

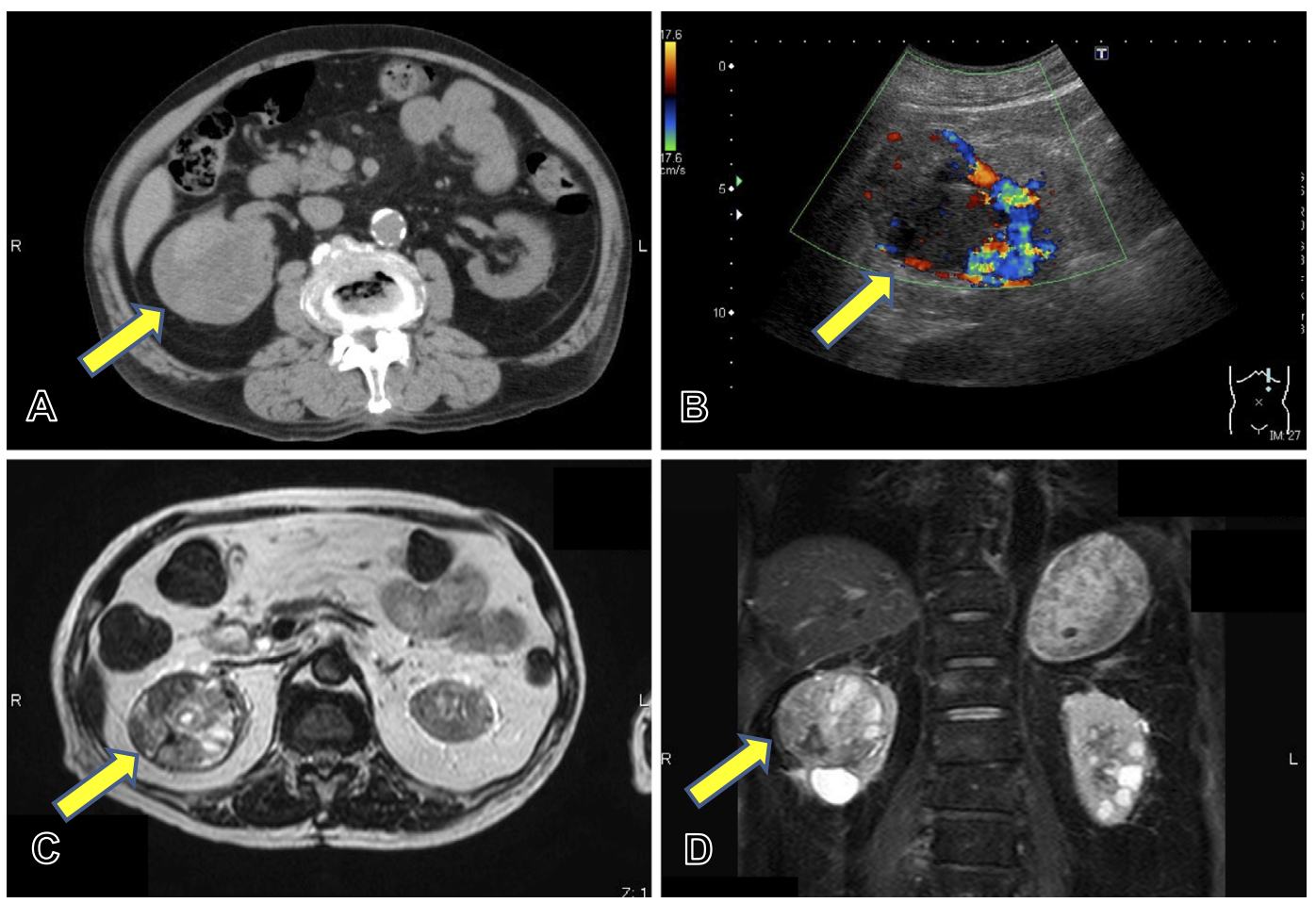

Figure 1. Representative radiological pictures of the renal cell carcinoma. (A-D) A mass with a diameter (approximately $6 \times 6 \mathrm{~cm}$ ) in the right kidney is observed in the axial view, suspected to be a renal tumor, by unenhanced computed tomography (A), abdominal ultrasound (B), and magnetic resonance imaging $(\mathrm{C}, \mathrm{D})$ of the patient (arrows). The lesion was non-homogeneous and slightly lowdensity compared with the renal parenchyma. The mass did not progress over the renal fascia (A). The mass was identified as a low-echoic lesion with cystic components, and an ultrasonic blood flowmeter showed blood flow predominantly in the periphery (B). On axial (C) and coronal (D) T2weighted images, the mass showed a heterogeneous mixed-intensity signal and was suggested to include a capsule.

diabetes that was well controlled (HbA1c 6.4\%) via diet therapy and the administration of an $\alpha$-glucosidase inhibitor (150 mg of acarbose per day). However, during follow-up, his urinary protein level rapidly escalated from 1.93 to 5.29 g/gCre over a 6-month period. Without observing any symptoms, such as back pain or macroscopic hematuria, we performed radiological examinations, including abdominal ultrasound, to investigate the etiology underlying the change in his condition. These examinations revealed the presence of a renal tumor, which was subsequently confirmed via unenhanced computed tomography (CT) and magnetic resonance imaging (Fig. 1).

We referred the patient to the urology department; however, a preoperative assessment of his condition revealed uncontrolled diabetes. Additional laboratory data showed no other abnormality, viral hepatitis, or elevation of autoimmune antibody levels, instead only showing a marked increase in his HbAlc level from $6.4 \%$ to $8.5 \%$ (Table, Fig. 2). At the same time, the levels of urinary $\mathrm{N}$-acetyl- $\beta$ D-glucosaminidase (NAG), a marker of tubular damage (8), and serum creatinine were also increased in comparison with previously measured values (Fig. 2). To manage his perioperative complications, we considered it necessary to improve his glycemic control and manage the sudden worsen- ing of diabetes; we therefore administered and adjusted his insulin dose and noted that he required a surprisingly high dose of medication. After consulting with the endocrinology department, he was administered up to 54 units of insulin per day to facilitate surgical resection of the renal tumor (Fig. 3).

After successful resection, the tumor was pathologically diagnosed as clear renal cell carcinoma (RCC). Owing to the necessary uni-nephrectomy and his originally decreased renal function, the patient subsequently required permanent RRT. Nevertheless, he unexpectedly exhibited dramatically improved diabetic control, such that he ceased being insulindependent. By the time of discharge, the patient required no diabetic medication (Fig. 3).

We wondered if IL-6 was related to the drastic change in insulin resistance after the surgery. Therefore, we performed immunostaining for IL-6 to investigate the etiology underlying the patient's worsened diabetes. The results of this analysis showed the cancer to be IL-6-positive, while the remaining non-cancerous kidney was found to be IL-6negative (Fig. 4). In addition, the pathological analysis of the non-cancerous kidney showed diffuse accumulation of mesangial matrix, termed diffuse lesion of diabetic nephropathy, with marked intimal thickening in the interlobular ar- 
Table. Laboratory Findings.

\begin{tabular}{|c|c|c|c|}
\hline \multicolumn{2}{|l|}{ hematology } & \multicolumn{2}{|l|}{ Serology } \\
\hline White blood cells & $11,200 / \mu \mathrm{L}$ & $\mathrm{IgG}$ & $1,200 \mathrm{mg} / \mathrm{dL}$ \\
\hline Hemoglobin & $10.2 \mathrm{~g} / \mathrm{dL}$ & $\operatorname{Ig} \mathrm{A}$ & $311 \mathrm{mg} / \mathrm{dL}$ \\
\hline Platelets & $253 \times 10^{3} / \mu \mathrm{L}$ & $\operatorname{IgM}$ & $252 \mathrm{mg} / \mathrm{dL}$ \\
\hline \multicolumn{2}{|l|}{ Blood chemistry } & $\mathrm{C} 3$ & $106 \mathrm{mg} / \mathrm{dL}$ \\
\hline Total protein & $6.7 \mathrm{~g} / \mathrm{dL}$ & $\mathrm{C} 4$ & $46 \mathrm{mg} / \mathrm{dL}$ \\
\hline Albumin & $3.2 \mathrm{~g} / \mathrm{dL}$ & CH50 & $50 \mathrm{U} / \mathrm{L}$ \\
\hline Aspartate aminotransferase & $14 \mathrm{U} / \mathrm{L}$ & Antinuclear antibody & $\times 40$ \\
\hline Alanine aminotransferase & $15 \mathrm{U} / \mathrm{I}$ & Anti-dsDNA & Negative \\
\hline A & 15 U/L & MPO-ANCA & Negative \\
\hline$\gamma$-glutamyl transferase & $1510 / \mathrm{L}$ & PR3-ANCA & Negative \\
\hline Lactate dehydrogenase & $18510 / \mathrm{L}$ & Anti-GBM & Negative \\
\hline Sodium & $140.4 \mathrm{mEq} / \mathrm{L}$ & Anti-HIV antibody & Negative \\
\hline Potassium & $5.5 \mathrm{mEq} / \mathrm{L}$ & Anti-HCV antibody & Negative \\
\hline Chloride & $\begin{array}{r}106.7 \mathrm{mEq} / \mathrm{L} \\
91 \mathrm{mo} / \mathrm{dI}\end{array}$ & HBs antigen & Negative \\
\hline Phosphate & $4.3 \mathrm{mg} / \mathrm{dL}$ & \multicolumn{2}{|l|}{ Urinalysis } \\
\hline Blood urea nitrogen & $71.5 \mathrm{mg} / \mathrm{dL}$ & $\mathrm{pH}$ & 6.0 \\
\hline Creatinine & $4.34 \mathrm{mg} / \mathrm{dL}$ & Occult blood & $1+$ \\
\hline Amylase & 97 IU/L & Glucose & Negative \\
\hline $\mathrm{TSH}$ & $5.66 \mu \mathrm{IU} / \mathrm{mL}$ & White blood cells & $2+$ \\
\hline Free $\mathrm{T} 4$ & $0.94 \mathrm{ng} / \mathrm{dL}$ & Urine protein & $5.05 \mathrm{~g} / \mathrm{gCr}$ \\
\hline C-reactive protein & $2.55 \mathrm{mg} / \mathrm{dL}$ & Bence-Jones protein & Negative \\
\hline \multicolumn{2}{|l|}{ Sugar test } & NAG & $28.8 \mathrm{U} / \mathrm{gCr}$ \\
\hline Fasting blood glucose & $131 \mathrm{mg} / \mathrm{dL}$ & \multicolumn{2}{|l|}{ Urinary sediments } \\
\hline Hemoglobin A1c & $8.5 \%$ & Red blood cell & 5-9/HPF \\
\hline Insulin (fasting) & $3.0 \mu \mathrm{U} / \mathrm{mL}$ & White blood cell & 20-29/HPF \\
\hline \multirow[t]{2}{*}{ C-peptide (fasting) } & $3.6 \mu \mathrm{g} / \mathrm{L}$ & Hyaline cast & 5-19/100LPF \\
\hline & & Epithelial cast & $1-4 / 100 \mathrm{LPF}$ \\
\hline
\end{tabular}

TSH: thyroid-stimulating hormone, T4: thyroxine, Ig: immunoglobulin, C3: complement component 3, C4: complement component 4, HBe: hepatitis B envelope, CH50: 50\% hemolytic complement unit, AntidsDNA :anti-double stranded DNA antibody, MPO-ANCA: myeloperoxidase-antineutrophil cytoplasmic antibodies, PR3-ANCA: Proteinase 3-antineutrophil cytoplasmic antibodies, Anti-GBM: anti-glomerular basement membrane antibodies, HIV: human immunodeficiency virus, HCV: hepatitis C virus, HBs: hepatitis B surface, NAG: N-acetyl- $\beta$-D-glucosaminidase, HPF: high power field, LPF: low power field

teries and marked hyalinosis in small arterioles (Fig. 5). These findings confirmed diabetic kidney disease.

\section{Discussion}

The hyperglycemic condition exhibited by the patient in the present study was likely indicative of a paraneoplastic syndrome, i.e., a clinical manifestation in an organ (such as the kidney or the endocrine system) that is indirectly caused by a tumor (9). For example, membranous nephropathy caused by a solid tumor is a typical paraneoplastic syndrome that affects the kidney (10), while those syndromes that affect the endocrine system include syndromes of inappropriate antidiuretic hormone secretion, such as hypercalcemia, Cushing's syndrome, and hypoglycemia (9). Notably, hyperglycemia in paraneoplastic endocrine syndromes is rare; however, the fact that resection of the RCC in the present study ameliorated the patient's insulin resistance supports the strong likelihood that it induced the observed marked increase in hyperglycemia.

The altered control of diabetes mellitus in the patient might have been affected by CKD progression, which has ambivalent effects on diabetic control. However, although CKD progression induces insulin resistance (11), amelioration of hyperglycemia is observed as CKD advances due to decreased clearance of insulin (12). The hemodialysis dependence after the uni-nephrectomy suggested aggravated renal dysfunction; however, even in the preoperative state, the patient presented with a severely decreased renal function (serum creatinine of $4.34 \mathrm{mg} / \mathrm{dL}$ corresponding to an estimated glomerular function of $11.0 \mathrm{~mL} / \mathrm{min} / 1.73 \mathrm{~m}^{2}$ ); therefore, the post-surgical deterioration in the renal function alone could not account for the decreased need for exogenous insulin (from 54 units to 0). Furthermore, in the preoperative state, the fasting $\mathrm{C}$-peptide value of the patient was $3.6 \mu \mathrm{g} / \mathrm{L}$, and thus, pancreatic insulin secretion in the patient was not much reduced. This refutes the possibility that insulin secretion was impaired by the tumor; however, the blood 
A
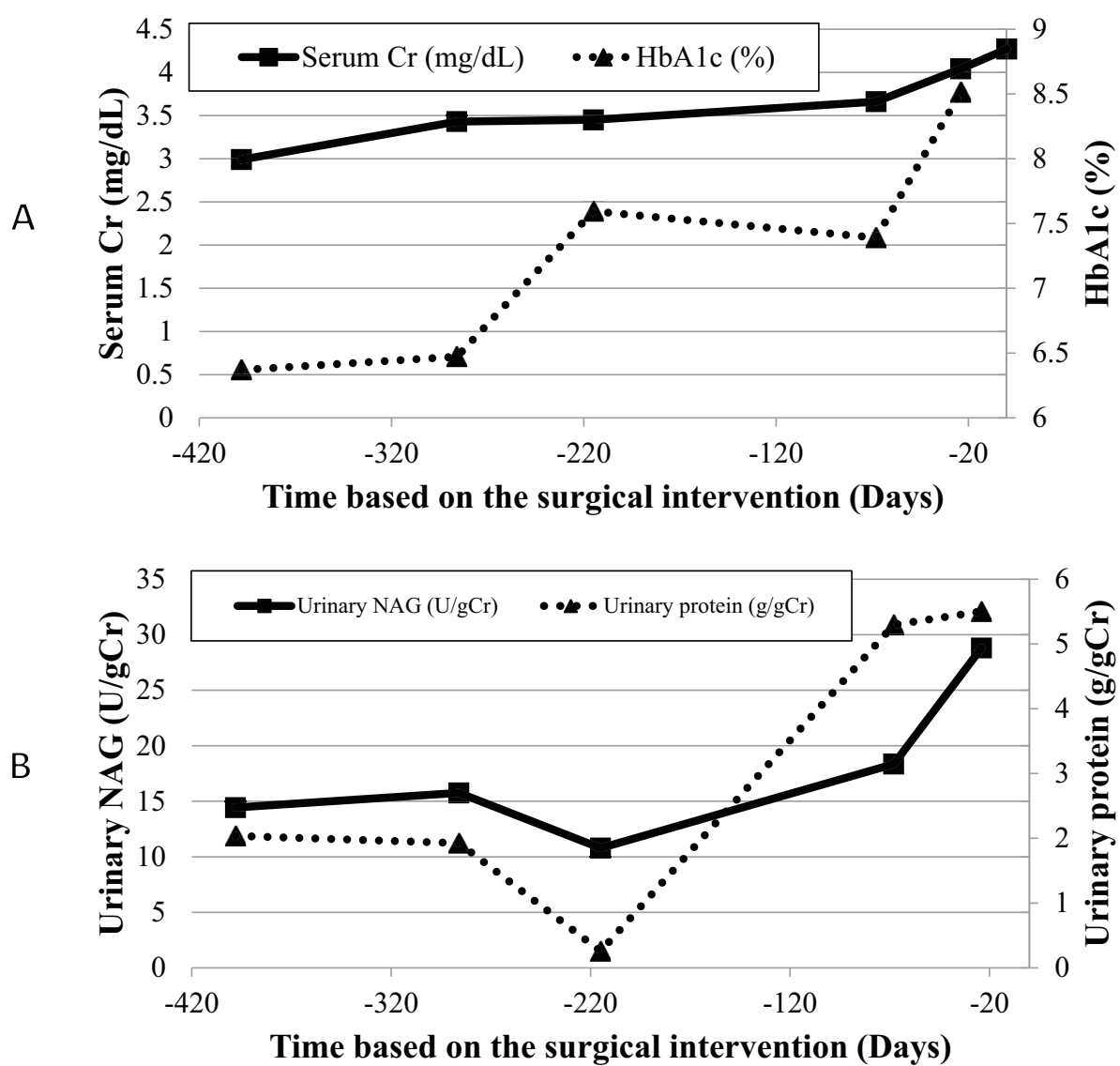

Figure 2. Trends in HbA1c values along with the serum creatinine, urinary NAG, and protein levels of the patient before surgery. (A) Trends in the values of HbA1c and serum creatinine of the patient. The values increased with the passage of time. (B) Trends in the values of urinary NAG and protein of the patient. The values increased with the passage of time. NAG: N-acetyl- $\beta$-D-glucosaminidase

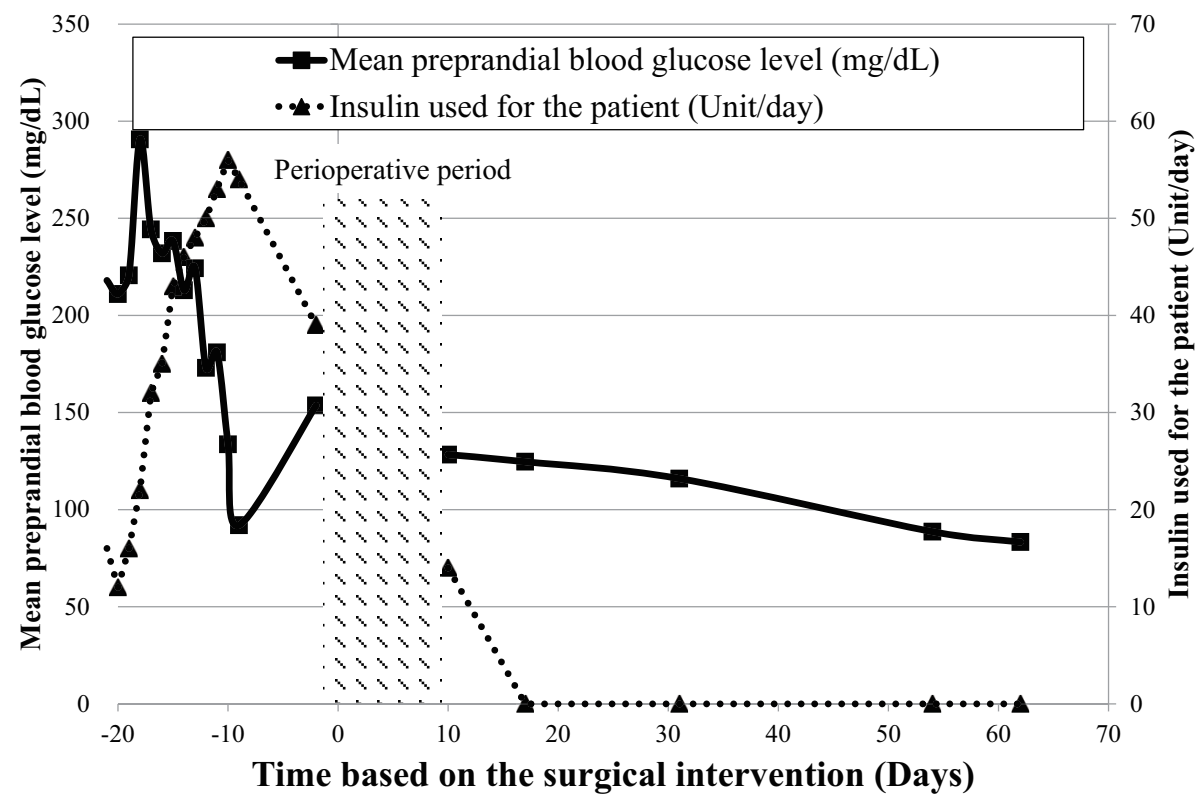

Figure 3. Mean pre-prandial blood glucose levels of and insulin units administered to the patient. Preoperatively, the patient's insulin usage was adjusted based on the glycemic level in order to facilitate surgical resection of the renal tumor, and the insulin requirement reached a maximum of 54 units per day at day-10 prior to surgery (it is important to note that the patient did not originally require insulin). However, postoperatively, there was no need to use insulin to control the patient's diabetes. 

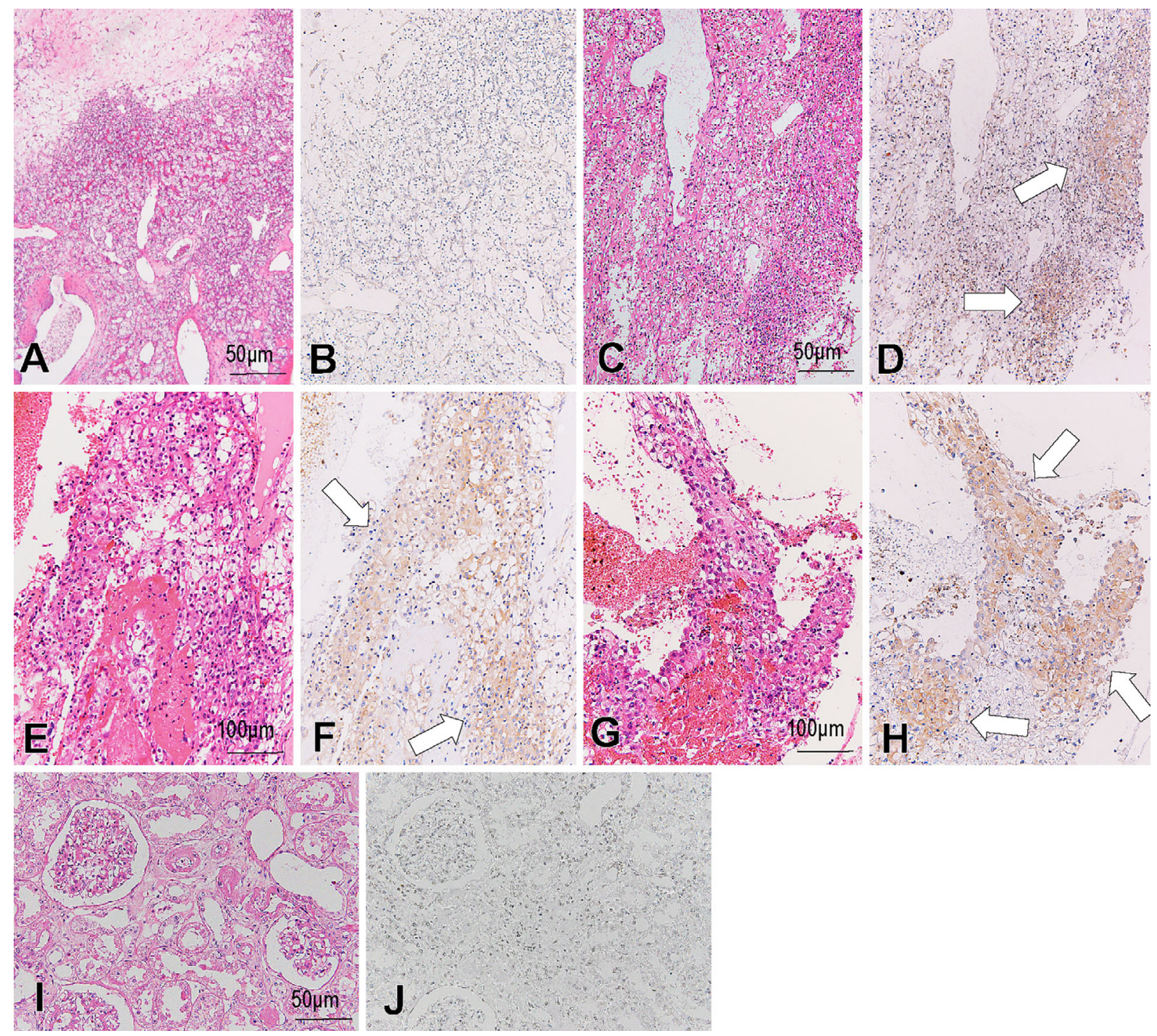

Figure 4. Histological analyses of the RCC and renal cortex without carcinoma. (A, C, E, G, I) Hematoxylin and Eosin staining of the RCC revealed characteristics typical of a renal clear cell carcinoma (A, C, E, G) and renal cortex without carcinoma (I). (B, D, F, H, J) Immunostaining for IL-6 resulted in little positive staining in the cytoplasm of RCC tissues with a G1 morphological grading (B), whereas staining was more prominent (arrows) in the cytoplasm of RCC tissues with a G3 morphological grading (D, F, H); negative staining was observed in the renal cortex without carcinoma $(J)$. Original magnification: $(A-D, I, J) \times 200,(E-H) \times 400$. RCC: renal cell carcinoma

glucose levels before and after the surgery suggested that the tumor had caused the increased insulin resistance. Moreover, the post-surgical changes in glucose values were drastic; the morning fasting glucose levels (100-150 mg/dL) were much lower than the preprandial glucose levels before lunch or supper (240-450 mg/dL) with the use of an $\alpha$ glucosidase inhibitor, while after resection, the morning fasting glucose levels (100-135 $\mathrm{mg} / \mathrm{dL})$ were comparable to the preprandial glucose levels before lunch or supper (95-180 $\mathrm{mg} / \mathrm{dL}$ ) without the use of insulin or any oral hypoglycemic agent. Thus, insulin resistance was a pivotal factor involved in the pathophysiology of uncontrolled diabetes mellitus in the preoperative state, and these facts support the possibility that the tumor induced a high insulin resistance. In summary, the patient very likely experienced a paraneoplastic endocrine syndrome that induced extreme hyperglycemia.

In addition to their interaction in paraneoplastic endocrine syndromes, diabetes and cancer have been shown to be closely linked in various other contexts as well. For example, studies have suggested that patients with diabetes experience an increased risk of developing $(13,14)$ and dying from cancer (15). Specifically, a recent meta-analysis showed that an underlying diabetes worsened the prognosis of patients with RCC (16); however, while these data support the existence of a relationship between diabetes and RCC development and/or progression, they have thus far failed to clarify the nature of such a relationship. As suggested here, modulation of the IL-6 expression may be one of the mechanisms underlying the link between the two conditions. IL-6 has been previously shown to be secreted by 


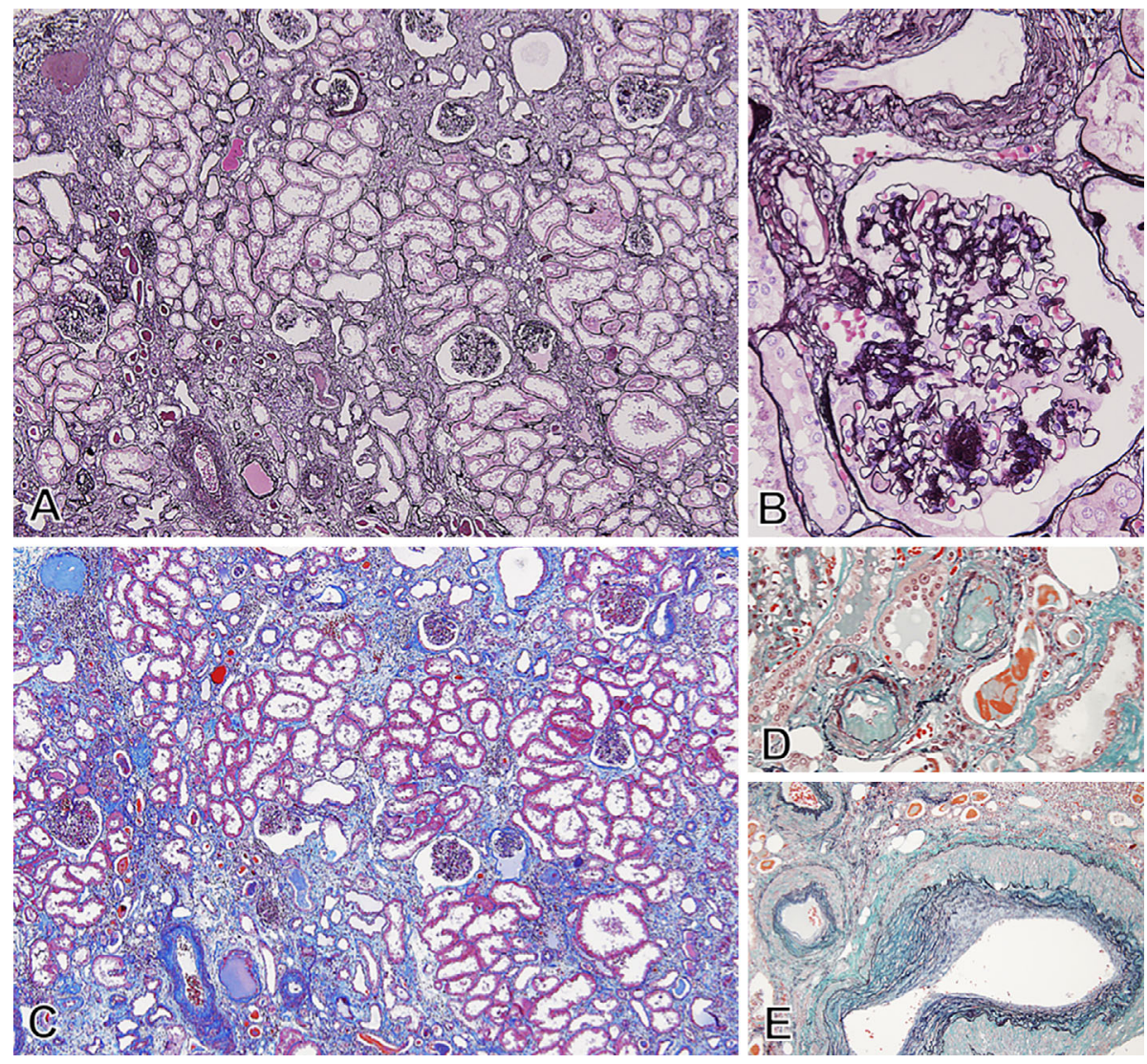

Figure 5. Histological analyses of renal cortex without carcinoma. (A-C) The non-cancerous kidney showed that some glomeruli underwent obsolescence with focal tubular atrophy and interstitial fibrosis. The remaining glomeruli with mild hypertrophy showed diffuse accumulation of mesangial matrix, termed diffuse lesion of diabetic nephropathy. The afferent arterioles showed arteriolar hyalinosis. (D, E) The arteries showed marked intimal thickening with elastofibrosis in the interlobular arteries and marked hyalinosis in small arterioles. A, B: Periodic acid-silver methenamine staining; original magnification $\times 40$ and $\times 400$, respectively; $C$ : Masson trichrome staining; original magnification, $\times 40$; D, E: Elastica Masson-Golder staining; original magnification, $\times 400$.

some RCCs and is now recognized as an important prognostic factor for RCC (17). Similarly, IL-6 has also been shown to both promote the development of diabetes (5) and be an independent predictor of cardiovascular events in patients with diabetes (17). Thus, the increased IL-6 expression may have aggravated the present patient's diabetes to the point of being uncontrolled and thereby worsened his prognosis. Notably, one of the limitations in our study is that we did not directly measure the patient's serum levels of IL-6; however, the immunohistochemical analysis of the patient's cancerous tissue revealed IL-6-positive cells, which had not been detected in cancer-free areas of the kidney (Fig. 4). This evidence strongly supports the contention that the cancer likely did produce IL-6 and thereby caused concomitant symptoms.

CKD progression has similarly been shown to be closely linked to cancer development. While ESKD has long been known to increase the risk of cancer development, recent studies have suggested that the risk of developing cancer may also be increased in the early stages of CKD (18). Notably, for those with diabetes, concurrent CKD increases the risk of cancer-related death (19); furthermore, cancer can accelerate CKD progression via the induction of AKI (20) since AKI can itself induce CKD progression (1). To date, the mechanisms underlying this latter effect have been poorly understood; however, they are thought to be likely associated with the production of various inflammatory factors and/or the onset of cachexia. In the present study, both the development of RCC and its subsequent removal contributed to the patient's transition from CKD to ESKD; however, his condition may have also deteriorated due in part to the cancer-induced aggravation of his diabetes. Taken together, these findings highlight the urgent need for continued research in the field of 'onco-nephrology' (21).

Several previously published case reports have suggested that elevated IL-6 production causes insulin resistance $(22,23)$. For example, a patient with lung cancer was previously reported to develop increased insulin resistance as a result of elevated plasma IL-6 levels (18). Furthermore, accumulating evidence suggests that increased IL-6 production promotes CKD progression (24) and increased urinary protein excretion (25), consistent with the fact that, in the 
present study, increased IL-6 production likely caused sufficient kidney damage to induce the observed increase in urinary protein excretion. While the mechanisms underlying these effects are not yet well understood, IL-6 and IL-8 (the predominant cytokines observed among the urinary proteins excreted by patients with nephrotic syndrome) have been shown to be toxic to renal tubular cells (26) and to promote CKD progression (27). In animal model and human cell experiments, IL-6 has been shown to disrupt the kidney function by deranging glomerular structures and damaging tubular cells $(24,28)$. The induced renal dysfunction subsequently leads to increased levels of serum and urinary IL6 (24), promoting further kidney damage in a vicious cycle.

Increased proteinuria was observed in the patient of this report in concomitance with the development of the RCC. The proteinuria was surely an initial sign, but its attribution to the tumor was difficult to confirm because he started to receive maintenance hemodialysis after his resection operation, making a urinalysis difficult to perform. Furthermore, the preoperative serum creatinine value was $4.34 \mathrm{mg} / \mathrm{dL}$, indicating that the patient was already near hemodialysis dependency before the surgery. Therefore, it is difficult to confirm whether or not the removal of the tumor ameliorated the renal tubular damage (a renal paraneoplastic syndrome), shown partially by the elevation of NAG. However, increased levels of NAG (see Fig. 2, in the preoperative state $28.8 \mathrm{U} / \mathrm{gCr}$, reference values 1.6-5.8 U/gCr) in the urine suggested severe tubular damage before the surgery. In addition, the patient had a 6-month history of serum creatinine deterioration from 3.45 to $4.34 \mathrm{mg} / \mathrm{dL}$ (see Fig. 2A); even though this deterioration seemed rapid, it was difficult to corroborate the involvement of the RCC. In conclusion, we considered that the RCC exacerbated his proteinuria and aggravated the kidney dysfunction, at least in part.

We carefully examined the patient for renal abnormalities given the sudden worsening of proteinuria, despite the fact that RCC is not usually identified via the observation of increased proteinuria; instead, it typically presents with flank pain, gross hematuria, and a palpable abdominal mass (29). In fact, RCC is often diagnosed as an incidental finding during abdominal ultrasound or CT that is performed for an unrelated reason (29) or via the identification of a paraneoplastic syndrome $(29,30)$. The results of the present study as well as a previous study that also reported the coexistence of RCC and severe proteinuria (31) suggest that systemic changes in CKD patients may be signs of tumors or paraneoplastic syndromes. However, future cohort studies are needed to further evaluate this association.

In summary, we herein report a case in which paraneoplastic complications caused by RCC resulted in the progression of both diabetes and CKD and thereby worsened the patient's prognosis. Although aggravation of urinary protein secretion and diabetes mellitus, increased IL-6 production, and RCC development have been previously postulated to be mutually related, the present study is the first to report their coexistence in a single patient. This report thus high- lights the need for both increased cancer screening in patients who present with an acute aggravation of diabetes or CKD and strict follow-up for patients with concomitant diabetes and $\mathrm{CKD}$, since both conditions are risk factors for cancer-related mortality.

The authors state that they have no Conflict of Interest (COI).

\section{References}

1. Singh P, Rifkin DE, Blantz RC. Chronic kidney disease: an inherent risk factor for acute kidney injury? Clin J Am Soc Nephrol 5: 1690-1695, 2010.

2. Christiansen CF, Johansen MB, Langeberg WJ, Fryzek JP, Sorensen HT. Incidence of acute kidney injury in cancer patients: a Danish population-based cohort study. Eur J Intern Med 22: 399-406, 2011.

3. Umanath K, Lewis JB. Update on diabetic nephropathy: core curriculum 2018. Am J Kidney Dis 71: 884-895, 2018.

4. Orgel E, Mittelman SD. The links between insulin resistance, diabetes, and cancer. Curr Diab Rep 13: 213-222, 2013.

5. Spranger J, Kroke A, Mohlig M, et al. Inflammatory cytokines and the risk to develop type 2 diabetes: results of the prospective population-based European Prospective Investigation into Cancer and Nutrition (EPIC)-Potsdam Study. Diabetes 52: 812-817, 2003.

6. Kaminska K, Czarnecka AM, Escudier B, Lian F, Szczylik C. Interleukin-6 as an emerging regulator of renal cell cancer. Urol Oncol 33: 476-485, 2015.

7. West HJ, Jin JO. JAMA oncology patient page. Performance status in patients with cancer. JAMA Oncol 1: 998, 2015.

8. Yamashita T, Noiri E, Hamasaki Y, et al. Erythropoietin concentration in acute kidney injury is associated with insulin-like growth factor-binding protein-1. Nephrology (Carlton) 21: 693-699, 2016.

9. Pelosof LC, Gerber DE. Paraneoplastic syndromes: an approach to diagnosis and treatment. Mayo Clin Proc 85: 838-854, 2010.

10. Davison AM. Renal diseases associated with malignancies. Nephrol Dial Transplant 16: 13-14, 2001.

11. Kobayashi S, Maesato K, Moriya H, Ohtake T, Ikeda T. Insulin resistance in patients with chronic kidney disease. Am J Kidney Dis 45: 275-280, 2005.

12. Mak RH, DeFronzo RA. Glucose and insulin metabolism in uremia. Nephron 61: 377-382, 1992.

13. Hemminki K, Li X, Sundquist J, Sundquist K. Risk of cancer following hospitalization for type 2 diabetes. Oncologist 15: 548-555, 2010 .

14. Inoue $M$, Iwasaki $M$, Otani $T$, Sasazuki S, Noda M, Tsugane S. Diabetes mellitus and the risk of cancer: results from a large-scale population-based cohort study in Japan. Arch Intern Med 166: 1871-1877, 2006.

15. Rao Kondapally Seshasai S, Kaptoge S, Thompson A, et al. Diabetes mellitus, fasting glucose, and risk of cause-specific death. N Engl J Med 364: 829-841, 2011.

16. Chen L, Li H, Gu L, et al. The impact of diabetes mellitus on renal cell carcinoma prognosis: a meta-analysis of cohort studies. Medicine (Baltimore) 94: e1055, 2015.

17. Lowe G, Woodward M, Hillis G, et al. Circulating inflammatory markers and the risk of vascular complications and mortality in people with type 2 diabetes and cardiovascular disease or risk factors: the ADVANCE study. Diabetes 63: 1115-1123, 2014.

18. Wong G, Hayen A, Chapman JR, et al. Association of CKD and cancer risk in older people. J Am Soc Nephrol 20: 1341-1350, 2009.

19. Chen DP, Davis BR, Simpson LM, et al. Association between chronic kidney disease and cancer mortality: a report from the 
ALLHAT. Clin Nephrol 87: 11-20, 2017.

20. Rosner MH, Perazella MA. Acute kidney injury in patients with cancer. New Engl J Med 376: 1770-1781, 2017.

21. Salahudeen AK, Bonventre JV. Onconephrology: the latest frontier in the war against kidney disease. J Am Soc Nephrol 24: 26-30, 2013.

22. Mizuhashi S, Nakamura K, Mori Y, Noda M, Nakanishi K. Insulin allergy and immunologic insulin resistance caused by interleukin-6 in a patient with lung cancer. Diabetes Care 29: 1711-1712, 2006.

23. Yoshiuchi I, Itoh $\mathrm{N}$, Nakano $\mathrm{M}$, Tatsumi $\mathrm{C}$, Yokoyama $\mathrm{K}$, Matsuyama T. Case report of Klinefelter's syndrome with severe diabetes, dyslipidemia, and stroke: the effect of pioglitazone and other anti-inflammatory agents on interleukin- 6 and -8 , tumor necrosis factor-alpha, and C-reactive protein. Diabetes Care 29: 1981, 2006.

24. Jones SA, Fraser DJ, Fielding CA, Jones GW. Interleukin-6 in renal disease and therapy. Nephrol Dial Transplant 30: 564-574, 2015.

25. Liu F, Guo J, Zhang Q, et al. The expression of tristetraprolin and its relationship with urinary proteins in patients with diabetic nephropathy. PloS One 10: e0141471, 2015.
26. Huang Z, Wen Q, Zhou SF, Yu XQ. Differential chemokine expression in tubular cells in response to urinary proteins from patients with nephrotic syndrome. Cytokine 42: 222-233, 2008.

27. Yamaguchi J, Tanaka T, Nangaku M. Recent advances in understanding of chronic kidney disease. F1000Res 4, 2015.

28. Okada A, Nangaku M, Jao TM, et al. D-serine, a novel uremic toxin, induces senescence in human renal tubular cells via GCN2 activation. Sci Rep 7: 11168, 2017.

29. Hsieh JJ, Purdue MP, Signoretti S, et al. Renal cell carcinoma. Nat Rev Dis Primers 3: 17009, 2017.

30. Palapattu GS, Kristo B, Rajfer J. Paraneoplastic syndromes in urologic malignancy: the many faces of renal cell carcinoma. Rev Urol 4: 163-170, 2002.

31. Yaghoubi F, Yarmohammadi M, Vasei M. Paraneoplastic proteinuria in papillary renal cell carcinoma; a case report. J Renal Inj Prev 5: 207-209, 2016.

The Internal Medicine is an Open Access journal distributed under the Creative Commons Attribution-NonCommercial-NoDerivatives 4.0 International License. To view the details of this license, please visit (https://creativecommons.org/licenses/ by-nc-nd/4.0/).

(C) 2019 The Japanese Society of Internal Medicine

Intern Med 58: 1953-1960, 2019 